\title{
是“偏岭石”还是 “天然烧变高岭石” ?*
}

\author{
何宏平 郭九皋 王辅亚 \\ (中国科学院广州地球化学研究所,广州 510640)
}

胡澄

(南京大学固体微结构物理实验室,南京 210093)

\section{关键词偏蛉石 变高岭石 红外吸收光谱 魔角旋转核磁共振}

偏岭石与天然烧变高岭石之争是粘土矿物学界多年来存在的一个问题. 刘长龄 ${ }^{[1 \sim 3]}$ 先后 多次报道在山西等地发现了一个粘土矿物新种—“偏岭石” (分子式为 $\mathrm{Al}_{2} \mathrm{O}_{3} \cdot 2 \mathrm{SiO}_{2} \cdot \mathrm{H}_{2} \mathrm{O}$ ), 并在其地质产状、光学特性、热学性质及红外光谱特征等方面给出了大量证据. 但真允 庆 $^{[4]}$ 认 为, 这是一种由煤自燃作用形成的天然烧变高岭石. 作者从 1990 年开始, 利用 ${ }^{27} \mathrm{Si},{ }^{27} \mathrm{Al} \mathrm{MAS}$ NMR 等手段对我国晋北等地的天然烧变高岭石和高岭石的热处理产物进行了研究, 并与 “偏 岭石” 作了对比.

在作者所研究的 3 个天然烧变高岭石样品中, 样品 $\mathrm{P}_{2}$ 采自晋北怀仁县某煤矿附近的石 炭、二叠系地层, 另外两个样品 $\mathrm{P}_{3}$ 和 $\mathrm{P}_{4}$ 由北京大学地质系朱如凯博士赠送, 其中 $\mathrm{P}_{3}$ 曾被认为 是 “偏岭石”. 3 个样品均带油脂光泽, 致密坚硬, 其中 $\mathrm{P}_{2}$ 和 $\mathrm{P}_{3}$ 略带灰色, $\mathrm{P}_{4}$ 略带浅红色.

\section{1 研究结果}

\section{1 化学成分}

从化学分析结果可知 (表 1), “偏岭石” 的化学成分和天然烧变高岭石的化学成分是基本 一致的. 刘长龄报道的天然变高岭石的 $\mathrm{Al}_{2} \mathrm{O}_{3}$ 含量偏高 ${ }^{[]}$, 主要是由于它与 $\mathrm{G}$ 层铝土矿伴 生, 其中混有少量铝土矿脱水后的产物. 很显然, 变高岭石中结构水的含量会因其受热温度 的不同而有一个较大幅度的变化, Mackenzie 等 ${ }^{[}$在研究变高岭石的结构时指出, 在 $570{ }^{\circ} \mathrm{C}$ 附

表 1 “偏岭石”和变高岭石的化学成分

\begin{tabular}{c|cccccccccccccc}
\hline 样品成分 & $\mathrm{SiO}_{2}$ & $\mathrm{Al}_{2} \mathrm{O}_{3}$ & $\mathrm{H}_{2} \mathrm{O}^{+}$ & $\mathrm{H}_{2} \mathrm{O}^{-}$ & $\mathrm{TiO}_{2}$ & $\mathrm{Fe}_{2} \mathrm{O}_{3}$ & $\mathrm{FeO}$ & $\mathrm{MnO}$ & $\mathrm{MgO}$ & $\mathrm{CaO}$ & $\mathrm{Na}_{2} \mathrm{O}$ & $\mathrm{K}_{2} \mathrm{O}$ & $\mathrm{P}_{2} \mathrm{O}_{5}$ & 总 计 \\
\hline 偏岭石 & 50.10 & 42.63 & 4.55 & 1.63 & 0.32 & 0.10 & 0.50 & - & 0.09 & 0.06 & 0.03 & 0.06 & 0.005 & 100.08 \\
(刘长龄) & & & & & & & & & & & & & & \\
$\mathrm{P}_{2}$ & 45.07 & 43.00 & 10.87 & 0.01 & 0.62 & 0.20 & 0.04 & 0.004 & 0.001 & 0.08 & 0.34 & 0.08 & 0.03 & 100.34 \\
$\mathrm{P}_{3}$ & 47.73 & 40.44 & 1.05 & - & 0.53 & - & 0.004 & 0.08 & 0.22 & 0.61 & 0.19 & 8.38 & - & 99.68 \\
$\mathrm{P}_{4}$ & 48.91 & 41.32 & 1.17 & - & 0.44 & - & - & 0.06 & 0.23 & 0.17 & 0.08 & 6.76 & - & 99.59 \\
天然烧变高岭石 & 51.15 & 41.44 & 4.12 & 0.05 & 0.49 & 0.18 & 0.60 & - & 0.14 & 0.12 & 0.88 & - & 0.006 & 99.18 \\
$\begin{array}{c}\text { (真允伕) } \\
\text { 天然烧变高岭石 } \\
\text { (刘长龄) }\end{array}$ & 31.69 & 55.37 & 5.08 & - & 2.66 & 2.54 & - & 0.04 & 0.28 & 0.64 & 0.64 & 0.36 & 0.06 & 99.34 \\
\hline
\end{tabular}

1995-05-09 收稿, 1995-08-05 收修改稿

* 国家自然科学基金资助项目 
近的大量脱羟后, 仍大约可有 $11 \% \sim 12 \%$ 的羟基残留在变高岭石结构中, 直至 $980{ }^{\circ} \mathrm{C}$ 左右, 这部分羟基才会完全脱失. 其实, 刘长龄在变高岭石和 “偏岭石” 的研究中也承认了这一点[2 5].

\section{2 差热分析 (DTA) 和热重分析 (TG)}

“偏岭石” 的 DTA 和 TG 曲线与天然变高岭石的 DTA 和 TG 曲线是一致的. 在 $980{ }^{\circ} \mathrm{C}$

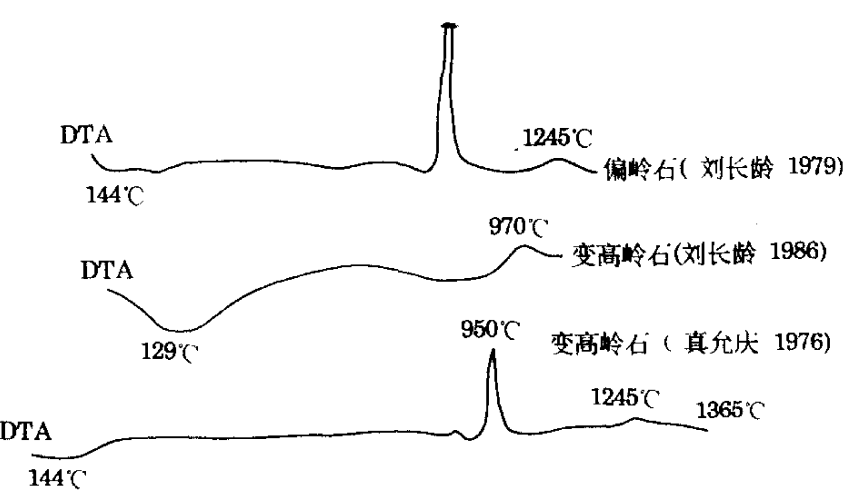

附近出现了尖锐的放热峰, 主要是由 于变高岭石结构中不稳定的 5 次配位 铝转变成了稳定的 4 次配位铝和 6 次 配位铝. 另外, 这些样品普遍在 $200{ }^{\circ} \mathrm{C}$ 以前出现了一宽吸热谷, 这是 由吸附水的脱失所致. 变高岭石的吸 附水脱失温度明显高于普通高岭石的 吸附水脱失温度, 这是由于在高岭石 脱失结构水时, 产生了大量断键, 并使

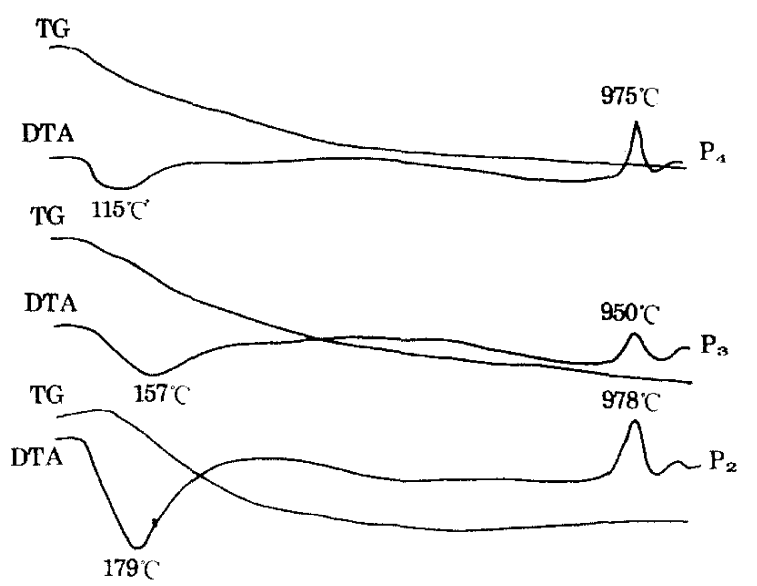
变高岭石结构中的铝氧层和硅氧层发 生了很大程度的畸变, 从而使其结构 单元层表面荷电, 而水又是极性分 子, 所以水分子被牢牢地吸附在其表 面而不易脱失。另外，在化学分析 中, 一般是将 $105{ }^{\circ} \mathrm{C}$ 以前脱失的水称 为吸附水 $\left(\mathrm{H}_{2} \mathrm{O}^{-}\right), 105{ }^{\circ} \mathrm{C}$ 以后脱失的 水称为结构水 $\left(\mathrm{H}_{2} \mathrm{O}^{+}\right)$, 所以, 在上述 样品的化学分析结果中, 结构水的含 量往往明显偏高.

\section{$1.3 X$ 射线衍射分析 (XRD)}

样品 $P_{2}, P_{3}$ 和 $P_{4}$ 的 $X$ 射线衍射

图 1 “偏岭石”、变高岭石 (刘长龄、真允庆) 以及 $\mathrm{P}_{2}, \mathrm{P}_{3}, \mathrm{P}_{4}$ 的 DTA 和 TG 图

结果与 “偏岭石” 的结果是完全一致 的, 除了在 $2 \theta=20^{\circ} \sim 30^{\circ}$ 位置出现了一弥散带, 无明显的衍射峰存在, 这表明样品由非晶质 组成.

\section{4 红外吸收光谱 (IR)}

$\mathrm{P}_{2}, \mathrm{P}_{3}, \mathrm{P}_{4}$ 和 “偏岭石” 的红外吸收光谱是十分相似的, 谱峰已明显宽化, 表明体系以非晶 相存在. 高岭石的 $3700 \sim 3600 \mathrm{~cm}^{-1}$ 区间内的 4 个麦基伸缩振动吸收峰 (即 $\gamma_{1}=3697 \mathrm{~cm}^{-1}$, $\gamma_{2}=3669 \mathrm{~cm}^{-1}, \gamma_{3}=3652 \mathrm{~cm}^{-1}, \gamma_{4}=3620 \mathrm{~cm}^{-1}$ ) 已全部消失, 取而代之, 在 $3440 \mathrm{~cm}^{-1}$ 及 $1636 \mathrm{~cm}^{-1}$ 附近出现了与吸附水相关的宽吸收峰. 在 $1060 \mathrm{~cm}^{-1}$ 和 $471 \mathrm{~cm}^{-1}$ 位置附近出现了 一个 Si-O 的吸收宽峰. 在 “偏岭石” 的红外吸收光谱中, 在 $750 \mathrm{~cm}^{-1}$ 位置出现了一弱吸收宽 峰, 刘长龄 ${ }^{[2]}$ 认为该宽峰由反映 $\mathrm{Si}-\mathrm{O}$ 键振动的特征峰 $\left(787 \mathrm{~cm}^{-1}\right)$ 和反映 $\mathrm{Al}-\mathrm{OH}$ 振动的 $750 \mathrm{~cm}^{-1}$ 吸收峰合并而成. 但作者在高岭石热处理产物的红外吸收光谱研究中发现, 该峰的 出现主要与莫来石的晶出和 $\mathrm{Al}_{2} \mathrm{O}_{3}$ 分凝相的形成有关, 也即该峰主要与 $\mathrm{Al}-\mathrm{O}$ 振动有关. 在 $\mathrm{P}_{2}$ 样品的红外吸收光谱中并未出现 $750 \mathrm{~cm}^{-1}$ 附近的吸收峰, 这主要与其受热程度有关. 高岭石 
热处理产物的红外吸收光谱表明,在 低温条件下的变高岭石中并未出现 $750 \mathrm{~cm}^{-1}$ 附近的吸收峰, 但在高温条 件下,在变高岭石的 IR 谱中出现了该 谱峰, 并且随着受热温度的升高, 该谱 峰变得越来越清晰. 所以, $P_{2}, P_{3}, P_{4}$ 和 “偏岭石”的 IR 谱是一致的,其间的 微小差异主要是由其受热程度不同而 造成的.

\section{$1.5{ }^{n 7} \mathrm{Al},{ }^{27} \mathrm{Si}$ 魔角旋转核磁共振研究 (MAS NMR)}

$\mathrm{P}_{2}, \mathrm{P}_{3}$ 和 $\mathrm{P}_{4}$ 的 ${ }^{27} \mathrm{Al}$ 的 ${ }^{29} \mathrm{Si}$ MAS

NMR 谱见图 2. 在 ${ }^{2} \mathrm{Si}$ MAS NMR 谱 中 $P_{2}, P_{3}$ 和 $P_{4}$ 的主峰位置分别在 $(\delta)-$
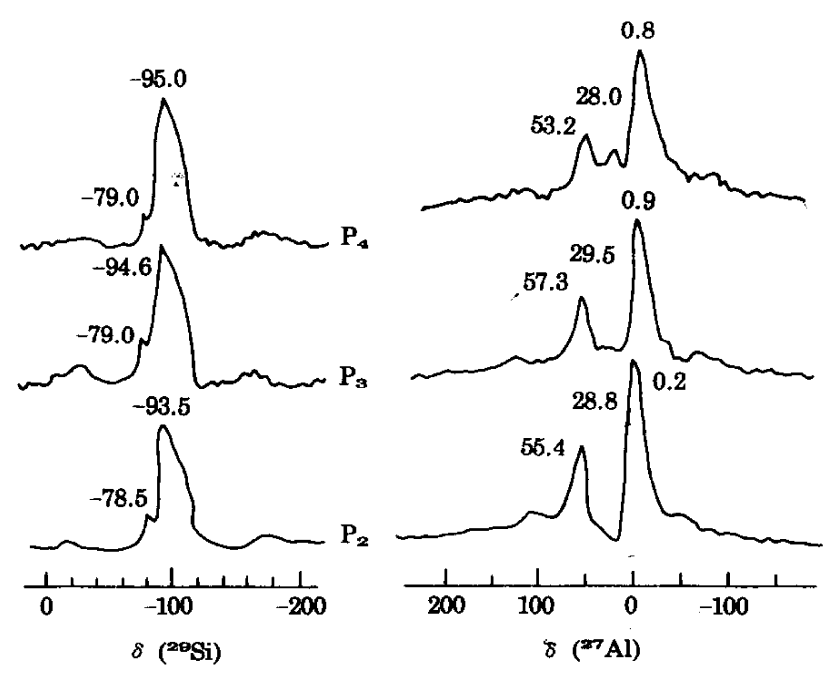

图 $2 \mathrm{P}_{2}, \mathrm{P}_{3}, \mathrm{P}_{4}$ 的 ${ }^{27} \mathrm{Al}$ (右) 和 ${ }^{29} \mathrm{Si}$ (左) MAS NMR 谱图 $93.5,(\delta)-94.6$ 和 $(\delta)-95.0$, 半高宽分别为 $(\delta) 25,(\delta) 26$ 和 $(\delta) 25$, 而高岭石 ${ }^{20} \mathrm{Si}$ 谱峰的重心位置 在 $(\delta)-91.1$ 附近, 半高宽为 $(\delta) 5$, 可见 $\mathrm{P}_{2}, \mathrm{P}_{3}$ 和 $\mathrm{P}_{4}{ }^{29} \mathrm{Si}$ 主峰的重心位置已向高场方向漂移, 并且 谱峰已明显宽化, 说明 $\mathbf{P}_{2}, \mathbf{P}_{3}$ 和 $\mathbf{P}_{4}$ 已有部分结晶相转变成了非晶质相. $\mathbf{P}_{2}, \mathbf{P}_{3}$ 和 $\mathbf{P}_{4}$ 主峰的化 学位移值表明, 此时体系中 $\mathrm{Si}$ 的聚合度仍为 $Q^{3}$, 即其中的 $\mathrm{Si}$ 仍以层状结构存在. 另外, 在 $\mathrm{P}_{2}$, $\mathrm{P}_{3}$ 和 $\mathrm{P}_{4}$ 的 ${ }^{29} \mathrm{Si}$ MAS NMR 谱中, 在 $(\delta)-79.0$ 位置附近, 出现了一弱峰, 该峰归因于变高岭石 经复水作用形成了水铝英石, 由于篇幅所限, 在此不作详述. 在 ${ }^{27} \mathrm{Al}$ MAS NMR 谱中, $\mathrm{P}_{2}, \mathrm{P}_{3}$ 和 $\mathbf{P}_{4}$ 的 4 次配位铝谱峰的重心位置分别在 $(\delta) 55.4$, $(\delta) 57.3$ 和 $(\delta)$ 53.2, 6 次配位铝谱峰的重心 位置分别在 $(\delta) 0.2,(\delta) 0.9$ 和 $(\delta) 0.8$. 与此同时, 3 个样品都出现了 5 次配位铝的弱信号, 其重 心位置分别在 $(\delta) 28.8,(\delta) 29.5$ 和 $(\delta)$ 28.0. $\mathrm{P}_{2}, \mathrm{P}_{3}$ 和 $\mathrm{P}_{4}$ 的 ${ }^{27} \mathrm{Al},{ }^{29} \mathrm{Si} \mathrm{MAS} \mathrm{NMR}$ 谱与普通高岭 石在 $500 \sim 550{ }^{\circ} \mathrm{C}$ 条件下热处理产物的 MAS NMR 谱一致, 属于典型的变高岭石结构.

\section{2 结论}

通过上述样品的表观、化学成分、差热分析(DTA)、热重分析 (TG), X 射线衍射 (XRD)、 红外吸收光谱 (IR)、 ${ }^{27} \mathrm{Al}$ 和 ${ }^{2} \mathrm{Si}$ 魔角旋转核磁共振 (MAS NMR) 等结果的对比研究, 作者认为 “偏岭石”并不是矿物新种, 而是天然变高岭石. 至于其成因, 很可能是受煤自燃作用所致.

\section{参 考 文 献}

1 刘长龄, 刘德业, 张 甫等. 偏岭石 - 粘土矿物新种. 科学通报, 1963, (10): 59 62

2 刘长龄. 偏岭石新原料的半晶质矿物性质及加热相变与工业利用问题. 硅酸盐, 1979, (1): 3 12

3 刘长龄. 晋北煤层夹矸粘土岩、偏岭石及紫研的物质来原与成因. 沉积学报, 1990, 8(1): 65 78

4 真允庆. 一种经过天然焙烤粘土岩的初步研究. 山西冶金地质, 1976, (4): $38 \sim 48$

5 刘长龄. 变高岭石在自然界的发现. 地质找矿论丛, 1986, (2): $70 \sim 76$

6 Mackenzie K J D, Brown I W M, Meinhold R H et al. Outstanding problems in the kaolinite-mullite reaction sequence investigated by ${ }^{2} \mathrm{Si}$ and ${ }^{27} \mathrm{Al}$ solid-state nuclear magnetic resonance: I. metakaolinite. J Am Ceram Soc, 1985, 68(6): $293 \sim 297$ 